\title{
Clínica sensível À Cultura popular na atenção ao SOFRIMENTO PSÍQUICO GRAVE
}

\author{
Ileno Izídio da Costa ${ }^{\star}$; Filipe Willadino Braga \\ Universidade de Brasília, Brasília, DF, Brasil
}

\begin{abstract}
RESUMO
Este estudo problematiza a atenção em saúde mental, resgatando a cultura popular como forma de encontro afetivo, cuidado e criação na clínica do sofrimento psíquico grave. Por meio de reflexão teórica, articularemos o conceito de cultura popular à noção de presença sensível e ambiente suficientemente bom. Compreendemos a cultura popular, no campo da saúde mental, pelo jogo do conformismo e da resistência frente à cultura hegemônica. Ressaltamos a importância de uma atenção sensivel aos modos de expressão da cultura popular no cotidiano dos serviços de saúde mental, a partir de uma postura ética e estética frente ao sofrimento psíquico grave.

Palavras-chave: reforma psiquiátrica; presença sensível; sofrimento psíquico grave; cultura popular
\end{abstract}

\section{TOWARDS CLINICAL CARE WHICH IS SENSITIVE TO POPULAR CULTURE IN THE CASE OF SEVERE PSYCHIC SUFFERING}

\begin{abstract}
This study inquires on mental health care, recovering popular culture as a means of finding affectivity, care and creation in the clinical care of severe psychic suffering. We will articulate the concept of popular culture to the notion of sensitive presence and a "sufficiently good environment" by the means of theoretical reflexion. We understand popular culture, within the field of mental health, as the game of conformism and resistance. We emphasize the importance of providing care which is sensitive to popular culture's means of expression, in the daily attention dispensed in mental health institutions, as well as an ethical and aesthetic attitude towards severe psychic suffering.
\end{abstract}

Keywords: psychiatric reform; sensitive presence; severe psychic suffering; popular culture.

\footnotetext{
‡ Endereço para correspondência: Universidade de Brasília, Instituto de Psicologia, Departamento de Psicologia Clínica. Campus Universitário, ICC Sul, Bloco A Asa Norte 70910900 - Brasilia, DF-Brasil.E-mail: ileno@unb.br, filipewbraga@yahoo.com.br.
} 


\section{INTRODUÇÃo}

No campo da saúde mental, no Brasil, encontramos uma conjuntura de lutas políticas pela consolidação da Reforma Psiquiátrica, desde a promulgação da Lei $n^{\circ} 10.216$, de 2001, até a realização da IV Conferência Nacional de Saúde Mental em 2010, que surgiu do processo histórico de organização política dos diversos segmentos integrantes dos movimentos sociais pela luta antimanicomial. Aquela conferência pautou a necessidade de a atenção psicossocial ser construída intersetorialmente, na progressiva substituição dos aparatos asilares-manicomiais pelos serviços de atenção psicossocial (BRASIL, 2010; PITTA, 2011).

Observamos avanços na construção da Reforma Psiquiátrica Brasileira, com considerável aumento de serviços substitutivos, e a busca pela reorientação da atenção à saúde mental pelo paradigma da clínica psicossocial. Segundo levantamento realizado pelo Ministério da Saúde (BRASIL, 2011), em 2002, havia 424 Centros de Atenção Psicossocial - CAPS, no Brasil, e, em 2010, esse número cresceu para 1.650, com redução expressiva também de leitos psiquiátricos e surgimento de outras iniciativas de desinstitucionalização. Apesar dos indicativos quantitativos, e de vir sendo consolidada a rede de atenção psicossocial em algumas regiões do Brasil, um dos principais desafios atuais é trazer essas mudanças para o cotidiano dos serviços substitutivos aos hospitais psiquiátricos.

Além disso, apontamos críticas às práticas manicomiais, mesmo na lógica da atenção psicossocial em serviços substitutivos ao modelo hospitalocêntrico-manicomial. Alverga e Dimenstein (2006) mostram que existem modos de perpetuação do que conceituam como "desejos de manicômio" no cotidiano dos serviços substitutivos, referindo-se não apenas a estratégias explícitas de confinamento da loucura, mas ao desejo de controlar, normatizar e disciplinar a diferença na sociedade de modo geral. Assim, é necessário um novo lugar sociopolítico-conceitual e cultural para a loucura, no qual o não enclausuramento seja analisado de modo micropolítico, a partir das relações de controle e disciplinamento, inscritas nem sempre de modo explícito ou discursivo (ALVERGA; DIMENSTEIN, 2006; GUATTARI, 1987). Com isso, acreditamos que é necessário pensar um novo lugar cultural e existencial para os sujeitos em sofrimento psíquico grave, tanto em relação à estigmatização, quanto em relação à possibilidade de os serviços substitutivos de saúde mental serem espaços de reconstrução histórica e de reposicionamento do sujeito em relação a seu destino e a seus desafios existenciais.

Neste estudo utilizamos o termo "sofrimento psíquico grave", com o objetivo de adotar referencial psicopatológico que busque indicadores para além da sintomatologia, ao conceituar o "sofrimento psíquico grave" como modo de estar no mundo, fenômeno existencial humano - de cunho interno, relacional e dinâmico - permeado pela vivência de angústia (COSTA, 2010). Nessa perspectiva, a angústia surge como dimensão central, já que o indicativo grave refere-se à intensidade do sofrimento existencialmente e subjetivamente, e não enquanto conjunto de sinais e sintomas previamente definidos por construtos fixos. A noção de sofrimento pode ser entendida: 
[...] a partir da relação com o outro, e é uma resposta que o sujeito tem ao pertencer ao espaço afetivo, relacional, histórico e social. Ainda que os sintomas expressos pelo sujeito sejam semelhantes aos de outras pessoas, a manifestação subjetiva do sofrimento é sempre exclusiva do indivíduo e irredutível, ou seja, impossível de ser enquadrada em uma classificação geral (COSTA, 2010, p. 60).

A partir dessas discussões, pretendemos desenvolver uma reflexão teórica na qual discutiremos modos de atenção ao sofrimento psíquico grave, a partir dos conceitos de presença sensível e cultura popular. Esse estudo problematiza a clínica do sofrimento psíquico grave pela ótica da cultura e das lutas populares, resgatando a cultura popular como modo de cuidado e criação na clínica. Em estudo anterior (BRAGA, 2012), apontamos a cultura popular como recurso clínico aos serviços de saúde mental. Com a utilização da metodologia de construção narrativa de pessoa em sofrimento psíquico grave, foi discutida a necessidade de reconhecimento aos mecanismos próprios de autoria dos produtores da cultura popular, assim como suas formas de conceber sua experiência de sofrimento. Portanto, o estudo da cultura popular como recurso clínico, aponta para novas possibilidades de reconhecimento dos sujeitos em sofrimento psíquico grave para além da estigmatização e exclusão social.

Pontuamos a necessidade de o cotidiano dos serviços substitutivos em saúde mental fundamentar-se em uma postura de cuidado, pelo encontro afetivo e sensível aos ritmos e rumos corporais dos sujeitos em sofrimento psíquico grave (KUPERMANN, 2008). Buscaremos traçar os referenciais da educação popular de Paulo Freire (1992, 2005[1974], 2011[1976]) que remetem ao conceito de cultura popular, estabelecendo como este pode ser compreendido no campo da saúde mental. A partir dessas considerações, nos questionamos sobre a possibilidade de uma atenção sensível ao sofrimento psíquico grave que ofereça recursos ao desafio da desinstitucionalização da loucura.

\section{COMPREENDENDO A CULTURA POPULAR COMO RECURSO CLÍNICO NA SAÚDE MENTAL}

Ao discutirmos a atenção ao sofrimento psíquico grave dentro do Sistema Único de Saúde - SUS, existe a necessidade de problematizar alguns dos referenciais da reforma psiquiátrica, partindo da cultura e das lutas populares (VASCONCELOS, 2008). Ao traçar um panorama histórico, Calado (1999) discute o conceito de "popular", desde a Idade Média, tendo como questão central uma posição subversiva em relação ao controle social e à hegemonia, afirmando sua posição de resistência e afirmação. O lançamento do Manifesto do Partido Comunista, por Marx (1999[1847]) delimita o popular enquanto consciência de classe, utilizando-se da chamada à união do proletariado no contexto da Revolução Industrial. Nesse sentido, existe demarcação política clara de reconhecimento do fazer dos grupos populares e da noção de consciência de classe, estabelecendo diretrizes para a construção de um projeto popular de sociedade. 
Neste estudo empregamos a definição de Cultura pela Educação Popular, que tem grande influência sobre a construção teórica que propõe a construção "com" os grupos populares como "trabalho social" (FREIRE, 2011[1976]), em substituição ao assistencialismo na elaboração de projetos e/ou pesquisas "para" esses grupos. Desse modo, abre-se o campo do diálogo enquanto possibilidade de relativização do saber científico e da necessidade de estar com os grupos populares, na construção de políticas públicas, investigação científica, práticas educativas e clínicas. É interessante perceber que, nas experiências de alfabetização por meio da educação popular no Chile, Freire (1983[1967]) comenta a função catártica no funcionamento dos Círculos de Cultura e a decodificação das situações existenciais pelos educandos, já que a decodificação dessas situações implicava em refletir sobre a própria existência e sobre a condição humana (LIMA, 1981). Portanto, para além da aquisição de técnicas de leitura e escrita, tinha como objetivo o desenvolvimento da criticidade e mobilizava vivências de sofrimento, esperança e construção coletiva, entre outras.

A educação popular traz enorme mudança no conceito de popular, compreendendo-o não apenas direcionado àqueles que fazem parte das classes populares, mas a todos comprometidos com o processo de libertação daqueles que vivem em situação de opressão, como desafio ontológico de autonomização. Freire (2005[1974]) compreende o oprimido, não enquanto categoria estática ou apenas pela sua oposição em relação aos opressores, mas permeado por relações construídas no cotidiano entre os diferentes grupos sociais a partir da unidade dialética entre sua dimensão subjetiva e objetiva. Destaca sua concepção de ser humano focada na processualidade, reconhecendo o sujeito em sua incompletude como possibilidade de diálogo e abertura à alteridade.

Com relação à noção de ação cultural, Freire (2011[1976]) compreende uma práxis (reflexão-ação) orientada pela ação cultural para a liberdade na construção de um sujeito político e amoroso, regido pelo respeito ao outro e com vocação humana de "ser mais". Estudando a ação cultural inscrita na unidade dialética subjetivo-objetivo, afirma que ad-mirar o mundo é objetivar um não-eu, enquanto inscrição da atividade de um sujeito na cultura como práxis. Portanto, traz a discussão do ser humano como ser "com" o mundo e não apenas "no" mundo, já que sua práxis implica a ação-reflexão do sujeito sobre o mundo, construindo-o por sua ação criativa dentro do que lhe é possível objetivamente, o que chama de "inédito viável".

Portanto, Freire afirma a necessidade de que o educador e pesquisador não tenham posição neutra, mas busquem métodos de ação política estimulando a reflexão crítica, a criatividade e a afetividade dos sujeitos, rompendo com posição fatalista que não vê a possibilidade de mudança. Com a denúncia da situação de opressão - construída na crítica e na reflexão - e o anúncio do "inédito viável", implicando projeto de ação, busca-se construir uma perspectiva utópica esperançosa recusando o futuro pré-fabricado (FREIRE, 2011[1976]). No campo da saúde mental, compreendemos que esse posicionamento pode ser colocado como uma atitude de trabalhar com o projeto de vida do sujeito, utilizando suas potencialidades e seus movimentos esperançosos em direção à saúde, mediados por instrumen- 
tos simbólicos da cultura popular. Em muitos casos, onde predominam a falta de esperança e de projeto de vida, o primeiro esforço é reconstruir essa possibilidade de projetar o futuro por meio de seu presente e passado, construído dialeticamente.

Ao mesmo tempo, podemos utilizar contribuições da Educação Popular na possibilidade de serem criados dispositivos clínicos com a metodologia dos Centros de Cultura nos serviços de saúde mental, de modo que seja eliminada a visão conteudista de saúde, na qual geralmente os serviços de saúde mental têm uma série de atividades para "ocupar" o dia do usuário, sem o estimulo à criticidade e autonomização. Desse modo, podemos trazer o debate de Freire (1974/2005) em relação às críticas à concepção bancária de educação, que reduzia o processo educacional ao ato de "depositar" conhecimentos nos alunos que eram vistos como passivos. O autor discutia a necessidade de compreender o educador também como educando, e vice-versa, de modo que fosse reconhecido seu papel ativo na construção do conhecimento.

Nos serviços de saúde também há a necessidade de que as ofertas de tratamento e reabilitação psicossocial não se reduzam a oferecer algo aos usuários, mas reconheçam seu papel ativo na construção de sua saúde e participação social. Com isso, é proposto que sejam estabelecidos espaços de construção criativa em relação a seu projeto terapêutico, pela convivência no cotidiano por meio do diálogo entre profissionais, usuários e familiares. A partir disso, pensamos que os serviços de saúde mental podem se tornar espaços para o fazer criativo e o estímulo à criticidade pela construção do sujeito com a cultura, para além da mera adaptação social ou o papel normatizador desta.

Chauí (1993), ao analisar a cultura popular no Brasil, pode trazer reflexões sobre muitos dos processos clínicos na atenção ao sofrimento psíquico grave, apesar de não dirigir seu estudo a esse foco. Um ponto fundamental defendido por ela é a diferenciação entre cultura popular e cultura de massa, já que a última reduz o povo a um todo indiferenciado, impossibilitando a compreensão das dimensões sociais e políticas da opressão em uma sociedade capitalista. A autora contextualiza que a cultura popular não se insere como prática alternativa à cultura dominante, mas enquanto resistência a esta, por meio de invenção e criatividade. O que a singulariza é o fato de ela compor um jogo de conformismo e resistência, utilizando a cultura hegemônica de modo inesperado, permitindo sua subversão e desconstrução. Desse modo, a cultura popular não pode ser compreendida enquanto totalidade, sendo permeada pela contradição e definida como:

Um conjunto disperso de práticas, representações e formas de consciência que possuem lógica própria (o jogo interno do conformismo, do inconformismo e da resistência) distinguindo-se da cultura dominante exatamente por essa lógica de práticas, representações e formas de consciência. (CHAUI, 1993, p. 25). 
É importante salientar que, para Chaui (1993), o conformismo é uma avaliação rigorosa dos limites subjetivos e objetivos encontrados em sua realidade, não sendo apenas uma concepção fatalista. Por outro lado, acreditamos que a resistência criativa surge como busca esperançosa do sujeito pela sua autonomização e acolhimento de seu modo de ser, fundamental para reconstrução histórica e inserção social do sujeito.

Percebemos que no campo da saúde mental, esse constante jogo de conformismo e resistência apresenta-se de modo muitas vezes despercebido pelos profissionais e usuários, sendo atribuído a outras questões, como a sintomatologia e referencias ao prognóstico atribuído somente à "doença”. Moffatt (1982) - ao relatar sua experiência na comunidade terapêutica de Peña - demonstra que usuários considerados "cronificados" e "incuráveis", ao serem convidados a movimentarem-se criativamente, mediados por instrumentos da cultura popular, demonstravam expressividade e vivências intensamente afetivas. Ao mesmo tempo, discute uma "Psicoterapia Popular" que, pela reinterpretação das técnicas europeias e pelo diálogo com as práticas populares de cuidado, busca criar dispositivos clínicos sensíveis às vivências das classes populares. Com isso, propõe novas formas alternativas de tratamento da loucura a partir da cultura popular, de modo que "A Comunidade desmascarou a submissão como falso critério de saúde mental e propôs outros padrões de sanidade para o povo: a sanidade de assumir sua identidade cultural e pessoal" (MOFFATT, 1982, p. 190).

Boltanski (1979) sinaliza que os grupos populares buscam os serviços de saúde prioritariamente por sua incapacitação para o trabalho, realçando a necessidade de protagonizarem seu destino como reconstrução histórica de seu cotidiano, reinterpretando seus sinais, sintomas e tratamento a partir de saberes da vivência nas classes populares. $\mathrm{O}$ autor realizou estudo com usuários de serviços de saúde da França, tanto em subúrbios de grandes cidades urbanas, quanto em comunidades rurais. Concluiu que os pacientes buscavam os centros de saúde e hospitais de forma dócil e eximindo-se de posições críticas sobre sua saúde, demonstrando postura de conformismo com sua passividade frente ao médico que detinha os conhecimentos naquela situação.

Por outro lado, Boltanski notou que, ao acompanhar o modo como os usuários seguiam ou não tais prescrições em suas casas, havia a reapropriação das prescrições dadas de modo criativo e inesperado por meio de significações da vivência dos sujeitos das classes populares. Assim, a medicação era administrada tal como compreendiam sua doença e associando seu uso à medicina popular. Em nosso estudo, utilizamos as contribuições de Boltanski em torno da dificuldade de o profissional compreender como o usuário se conforma com modos de invasão cultural ou resiste e reinterpreta seu tratamento a partir de sua subjetividade e práticas culturais.

Ropa e Duarte (1985) criticam a compreensão de Boltanski, ao afirmarem que essa não reconhece os saberes populares em relação à saúde como um campo distinto dos saberes eruditos. Argumentam também que Boltanski reduz as manifestações culturais próprias dos grupos populares à noção de cultura somática, na 
possibilidade de observar sensações corporais e torná-las verbalizáveis ao médico. Existe o risco de afirmar que para uma atenção à saúde nesse contexto, basta a utilização de técnicas não-verbais e ajustes nas estratégias de acessar esses sujeitos. Assim, não é reconhecido que a ineficácia das práticas terapêuticas na saúde mental também reporta à ausência de dispositivos clínicos que se proponham a uma contextualização sociocultural das práticas em saúde mental, de modo que essas não recorram a práticas etnocêntricas.

Concordamos com esses autores que a ineficácia das práticas psicoterapêuticas e psiquiátricas não ocorre apenas devido a inadequações técnicas, nem consiste em privação da linguagem, ou privação dos recursos dos sujeitos dos grupos populares, ao lidarem com problemas referentes ao campo da saúde mental. Também é necessário contextualizar que o estudo de Boltanski refere-se às classes trabalhadoras da França, as quais têm outras especificidades subjetivas e culturais e são atendidas por um sistema de saúde com organização completamente diferente do Sistema Único de Saúde - SUS. Por outro lado, acreditamos que a pesquisa de Boltanski abre possibilidades de estudo da relação entre os saberes eruditos e populares no campo da saúde, em seus tensionamentos e subversão frente às práticas biomédicas.

Já Vasconcelos (2008) problematiza como construir a atenção psicossocial baseada na cultura e lutas populares, retomando uma experiência na qual o movimento popular de uma pequena cidade de Minas Gerais reivindicou os modos de construir os serviços de saúde mental e pôde construir coletivamente as demandas clínicas e políticas que a comunidade trazia. Ao analisar dois projetos de saúde mental comunitária, o autor aponta que nos serviços públicos a busca por atendimento nem sempre apresenta elaboração da demanda - como muitas vezes acontece na busca de psicoterapia. No estudo de Vasconcelos, percebeu-se que os usuários nem sempre pediam ajuda espontaneamente, apontando a importância da disponibilidade do terapeuta para além dos espaços das consultas e grupos terapêuticos como dimensão de cuidado fundamental ao usuário. Nesse sentido, sinalizou-se a necessidade de contrato terapêutico mais flexível, que fosse sensível ao tempo do usuário e que permitisse a compreensão da relação terapêutica para além dos espaços delimitados.

Essas contribuições permitem o diálogo entre saberes psiquiátricos, psicológicos e as produções populares, abdicando da posição de superioridade da ciência frente a outros saberes no cuidado a modos de sofrimento psíquico grave. Isso não significa a renúncia a indicadores de atenção em saúde que tenham confiabilidade e sejam legitimados pelos sujeitos que buscam ajuda, mas, pelo contrário, consiste em reconhecer as práticas populares que existem no cotidiano dos sujeitos dos grupos populares. Nesse sentido, é necessário o cuidado com a aplicação de práticas de saúde apenas com mudanças técnicas e estratégicas a públicos que compartilhem outros sistemas simbólicos de ordenamento de realidade (ROPA; DUARTE, 1985). Utilizamos essas contribuições ao presente estudo na tentativa de ajustar os diferentes dispositivos clínicos da reforma psiquiátrica às manifestações próprias da cultura popular. 


\section{Presença sensível e a Clínica do setting na atenção ao}

\section{SOFRIMENTO PSÍQUICO GRAVE}

A psicanálise winnicottiana traz uma série de contribuições ao estudo do fenômeno saúde/doença e ao campo do sofrimento psíquico grave. Winnicott teve sua prática inicial como pediatra e, posteriormente, como psicanalista de crianças, jovens e adultos em consultório. Uma de suas obras na qual delimita ,de modo sucinto e direto a noção de indivíduo saudável, é a compilação de palestras realizadas por ele: Tudo começa em casa (WINNICOTT, 2011). Nele, inicia sua exposição informando que uma das principais contribuições da Psicanálise, já estabelecida por Freud, foi recusar a lógica da remissão dos sintomas para prestar atenção à capacidade de o paciente revelar-se a si mesmo. Apesar da contribuição freudiana, considera que a saúde não pode ser apenas compreendida pela referência à fixação às zonas erógenas, mas que apresenta íntima ligação com a maturidade do indivíduo, compreendida como movimento em direção à independência, processo de autonomização na batalha de manter-se vivo e continuar existindo.

Portanto, a saúde pode ser compreendida como o processo de adquirir senso de ser, senso de self e de sentir-se real. Para tanto, o bebê necessita receber do ambiente as funções de holding (sustentação) e do handling (manejo), desde os estágios iniciais da vida do bebê em sua relação com a mãe. A primeira função refere-se à sustentação dada pelo ambiente às necessidades do bebê em sua experiência de continuidade de ser, representando pela confiança e constância do ambiente, originadas no estado de preocupação materna primária (ABRAM, 2000). Portanto, diz respeito à possibilidade de o bebê receber suporte para sua formação egóica e entrada no campo dos fenômenos transicionais. Já o handling consiste na manipulação corporal e no contato com as necessidades corporais pela relação mãe-bebê, possibilitando que o indivíduo habite seu corpo e cumpra a tarefa da personalização no desenvolvimento emocional primitivo (WINNICOTT, 1993[1945]).

É importante situar que, por discutir os cuidados maternos, Winnicott faz referência ao cuidado oferecido pela mãe como função (maternagem), porém, no contexto analítico com adultos, utiliza a noção de ambiente suficientemente bom (WINNICOTT, 1993[1954]). Neste estudo, sempre que for discutida a relação mãe-bebê pela teoria winnicottiana, esta se refere a questões que serão atualizadas na relação transferencial e, portanto, que dizem respeito a todo o desenvolvimento do sujeito e ao setting analítico pensando na relação analista-analisando.

Com relação à provisão ambiental, Winnicott (1993[1952], 1993[1955]) discute a necessidade da adaptação ativa do analista ao indivíduo em sofrimento, situando as origens da psicose em fases anteriores ao estabelecimento do ser total, com ego constituído. Com isso, a construção do ambiente - não é espaço ideal e sem falhas - mas possibilidade de constância na adaptação ativa às necessidades do bebê, o que progressivamente vai dando-o a sensação de confiança no ambiente (WINNICOTT, 1993[1952]). Parte da noção de "mãe suficientemente boa", trazendo nas primeiras fases do desenvolvimento infantil a necessidade da "devoção" da mãe enquanto categoria sensível: 
Pode-se eliminar o sentimentalismo da palavra "devoção" e utilizá-la para descrever a característica essencial sem a qual a mãe não pode dar sua contribuição, uma adaptação sensível e ativa às necessidades de seu bebê, necessidades que no início são absolutas (WINNICOTT, 1993[1952], p. 376).

Winnicott situa a origem dos processos psicopatológicos e do sofrimento psíquico grave na inconstância e não adaptação do ambiente à ação criativa do bebê, não atingindo as metas do desenvolvimento emocional adulto: a integração, a personalização e as relações objetais (WINNICOTT, 1983[1963]; 2011). Discute o modo como a adaptação suficientemente boa do analista é recurso clínico no atendimento à psicose adulta e na prevenção à cronificação do quadro sintomatológico. Nesse sentido, ressalta a necessidade de o analista colocar-se como objeto subjetivo para o analisando, ao oferecer no ambiente aquilo que o analisando cria, sempre trazendo uma carga de alteridade em sua apresentação objetiva, o que configura a experiência de "ilusão" no desenvolvimento (WINNICOTT, 1992[1971]).

Kupermann (2008) chama a atenção aos ritmos e rumos corporais dos sujeitos e à dimensão comunicacional para além da fala e dos significantes, construída enquanto presença sensível. Essa clínica é embasada principalmente pelo que o autor chama de "tato", ao retirar esse conceito de Ferenczi (1992[1928]), como dimensão do sensível e da intuição que não se permite capturar pela racionalidade ou pela compulsão do analista em interpretar. Com isso, é retomada a dimensão estética da clínica, afirmando que "na clínica, todo saber veiculado sem tato é abusivo e violento." (KUPERMANN, 2008, p. 178). Faz referência ao fato de que, para os casos de sofrimento psíquico grave, o contexto (setting) é mais importante que a interpretação em si, permitindo que o analista possa acompanhar as manifestações inconscientes do sujeito em suas dimensões sensíveis, ampliando o conceito de transferência. É interessante observamos que, antes de o bebê compreender a linguagem discursiva e entrar no campo simbólico, ele consegue perceber a presença do outro, desde antes de seu nascimento, o que faz com que o "estar com", como intervenção clínica, permita dar contorno a experiências de falhas ambientais que estejam situadas nos estágios iniciais de desenvolvimento. Nessa perspectiva, o campo transferencial é visto como ponto de compartilhamento afetivo, no qual o analista é convidado a estar com o sujeito em sofrimento, ao invés de apenas interpretar a dinâmica transferencial, exigindo do analista disponibilidade afetiva, em detrimento à abstinência, à frieza e/ou ao distanciamento.

\section{É POSSÍVEL UMA ÉTICA DE SENSIBILIDADE À CULTURA POPULAR?}

Neste momento, buscaremos estabelecer um diálogo entre o sofrimento psíquico grave e a relação do sujeito na e com a cultura. Situaremos como esta pode ser fundamental como critério diferencial em relação à delimitação da gravidade do sofrimento e à possibilidade de serem criados recursos clínicos sensíveis às formas de o sujeito viver sua cultura em sua experiência singular e política. 
Quando Winnicott discute os quadros clínicos que exigem que o psicanalista tenha prática diferenciada em relação à técnica freudiana clássica, elenca cinco pontos importantes de serem considerados, dentre eles a "ausência de vida cultural" (WINNICOTT, 1983[1962]). As condições que podem exigir análise diferenciada são: o temor à loucura; o domínio do falso-self sobre o ser total; a tendência antissocial; quando uma figura materna ou paterna doente domina o quadro; e, por último, quando não há vida cultural, ou seja, quando o indivíduo não é capaz de viver sob a esfera dos fenômenos transicionais, sendo submisso ou alheio à realidade externa. É interessante notar neste trecho que, ao mostrar modos de sofrimento grave que necessitariam de manejo diferenciado do setting, a possibilidade de o sujeito ocupar o espaço potencial e estar vivendo criativamente com a cultura surge como um dos critérios definidores do tipo de análise diferenciada da técnica freudiana clássica, referindo-se ao surgimento da neurose de transferência no enquadre do consultório.

Com os questionamentos anteriores aplicados à vivência dos sujeitos em sofrimento psíquico grave em suas experiências culturais, acreditamos que não basta ajustar e controlar a sintomatologia do sujeito em sofrimento, mas é necessário que a própria sociedade seja alterada para permitir que o sujeito considerado louco possa ser acolhido em sua forma de expressão singular. Conforme Safra (1998) comenta, a loucura pode ser compreendida como a "ausência de cotidiano", já que o fato de sentir-se vivo e acontecer no mundo só são possíveis se o sujeito puder entrar no mundo de forma singular e pessoal, por meio de sua criatividade. O ser busca - pelo fenômeno da "ilusão" - encontrar elementos e proporções de si em sua cultura. Neste estudo, compreendemos que o sofrimento psíquico grave permeia o fato de o sujeito não conseguir inscrever modos de ser, em sua cultura, o que exige transformação cultural em uma clínica sensível à inserção do sujeito no e com o mundo.

A cultura pode ser compreendida como fruto da ação criativa do ser na construção do destinar-se pelo sujeito e no posicionamento deste sobre sua própria história (SAFRA, 2004). Assim, o analista deve colocar-se como alteridade ao analisando, permitindo que seu gesto criativo seja reconhecido como inédito e singular, ao mesmo tempo em que se situa dentro dos aspectos culturais e ancestrais. Safra aponta que, com esse posicionamento do analista, o sujeito pode encontrar o lugar de seu sofrimento, reposicionando-o eticamente sobre sua existência. O autor traz o conceito de "Idioma Pessoal" como a entrada no campo da linguagem do analisando, não apenas pela fala, mas em seu nível gestual e criativo, definindo-o como: "[...] a possibilidade de se compreender a maneira como formula as grandes questões da existência, o modo peculiar que ela tem de portar seu sofrimento e a maneira como sonha seu porvir". (SAFRA, 2004, p. 116). A partir dessa postura, pretende-se que o analista saia da posição de sujeito que detém o saber sobre o outro e possa ser "aprendiz da clínica" para construir caminhos existenciais ao sofrimento com o outro.

Portanto, como destaca Safra (1998), a experiência de loucura tem uma íntima ligação com o fenômeno da exclusão social e desenraizamento, exigindo que o analista pense sua intervenção orientada pela inserção social, recolocando o 
paciente frente à ruptura cultural que sofreu e não apenas restrita à sua dimensão pulsional. Acreditamos que o reconhecimento do gesto criativo do sujeito com seu caráter popular permite um processo de desvelamento do self pela integração de sua singularidade à construção coletiva e histórica. É importante contextualizar que, neste estudo, discutimos as especificidades das vivências dos sujeitos permeados pela cultura popular. Porém, esse autor discute tais questões como dadas pela condição humana, e não apenas como prática social.

Safra também explica que a organização psicótica é um dos destinos possíveis em relação à experiência de loucura, como dispersão de si em relação à perda de inscrição no espaço-tempo e desintegração. Assim, a psicose não é colocada como entidade nosológica ou estrutura definidora do psiquismo, mas como organização defensiva frente à impossibilidade de viver a experiência de loucura de modo criativo. A arte e outros modos de expressão cultural oferecem a experiência de não-integração, porém de modo criativo e sem ameaçar a continuidade do ser (GODOY, 2007; SAFRA, 1998). Com isso, percebemos a diferenciação entre as experiências de desintegração (nas quais há real ameaça de perda da unidade do self como nas estruturas esquizóides) e de não-integração (sobre a qual surge o impulso criativo) podendo ser vivida a experiência de sofrimento de modo saudável e que permita a ação do ser na cultura como união da relação mãe-bebê, referente à internalização da vivência de um ambiente suficientemente bom (WINNICOTT, 2011).

Compreendemos a manifestação inconsciente do sujeito como busca de integrar a necessidade do viver comunitário com a possibilidade de ser acolhido pelo outro como alteridade, possibilitando o reconhecimento de sua singularidade em sua transcendência. É nesse caminho, entre a vivência comunitária dos sujeitos dos grupos populares e as singularidades que permeiam seus modos de sofrer, que pode acontecer o encontro afetivo entre terapeuta e usuário. Nessa relação de estar com o sujeito em sofrimento - por meio da disponibilidade afetiva do terapeuta -, é necessário o cuidado para que a prática clínica não se torne meio de opressão, quando são propostas prescrições, interpretações e/ou orientações pelo profissional sem a presença sensível a seu viver com a cultura. Assim, estar com o outro consiste em intervenção clínica em si, já que é modo de posicionar-se em "comunidade de destino", permitindo novos posicionamentos existenciais (SAFRA, 2004).

Para problematizar esta questão, acreditamos que o analista deve ter postura ética que promova a integração do sujeito comunitário e singular (SAFRA, 2004), como possibilidade de existência política e de sofrer criador. Safra remonta aos dois conceitos de ética oriundos do ethos. O primeiro sentido refere-se à práxis ou costume; já o segundo, à morada e pátria. Safra versa sobre a ética da situação clínica em relação ao segundo sentido, caracterizando o cuidado como construção de uma morada para o sujeito que está em sofrimento.

A postura ética permite a formulação de uma morada às questões existenciais do sujeito, mesmo em sua dimensão misteriosa e indizível, portanto, não podendo reduzi-la à dimensão técnica ou verbal. Na situação clínica, existe a 
possibilidade de o sujeito ser acolhido como singularidade e, ao mesmo tempo, recolocar-se em "comunidade de destino". Safra (2004) define "comunidade de destino" pelo termo advindo do russo: Sobornost, que significa saber pré-subjetivo e pré-reflexivo, o qual revela a verdade do ser como acontecimento comunitário. Diz respeito ao ontológico, ao ser, conforme foi discutido anteriormente, de modo que as fraturas na possibilidade de habitar e participar da comunidade de destino geram modos de adoecimento ao ser humano.

Alguns autores da reforma psiquiátrica também trazem contribuições à construção de dispositivos clínicos que sejam sensíveis ao sofrimento psíquico grave, apontando possibilidades de acolher a existência nômade e esquizo (ROLNIK, 1997) dos diversos modos de sofrer, desconstruindo práticas normalizadoras e estigmatizadoras dos sujeitos, ao discutir uma noção de clínica ampliada, regida pela complexidade e experimentação (LANCETTI, 2008). Antonio Lancetti traz o conceito de "Clínica Peripatética" na atenção ao usuário no cotidiano dos serviços de saúde mental, ultrapassando os espaços demarcados de escuta e atendimento restritos a consultas e oficinas terapêuticas. Dessa forma, o profissional é chamado a agir no campo da cultura e no território existencial do usuário, privilegiando a continência oferecida pelo corpo do terapeuta, como meio de compreender as diversas formas de sofrer, constituindo-se como clínica artesanal e permeada pela surpresa. No campo da reforma psiquiátrica, tal reflexão é fundamental para não tornar a clínica dos serviços de saúde mental, restrita a práticas ambulatoriais burocratizadas por filas de esperas, refletindo na atenção fechada em si mesma, sem integração com outros níveis de atenção em saúde e para o diálogo interdisciplinar.

O sofrimento psíquico grave não tem como única causa sua sintomatologia, mas também a dificuldade em compreender que os singulares territórios do sujeito não cabem no enclausuramento do modo neurótico de subjetivação, como traz Rolnik (1997). Ao discutir o acompanhamento terapêutico, a autora permite a reflexão mais geral, apontando que o fundamental não é o espaço concreto da prática (consultório, rua e/ou casa), e, sim, que o analista tenha uma prática nômade, tomando a singularização e não a delimitação de fronteiras entre o dentro e o fora como princípio:

Deslocar-se concretamente - para fora do consultório, dos ambulatórios ou dos hospitais (sejam eles dos que funcionam dia e noite ou apenas de dia) - em nada garante uma sensibilidade ao fora como nascente de linhas de tempo e, menos ainda, uma capacidade de acolher a dor da desestabilização que o surgimento de tais linhas provoca. (ROLNIK, 1997, p. 95).

Assim, é na sensibilidade - como dimensão estética e não racionalizável - aos diferentes modos de sofrimento psíquico grave, que é possível o resgate da dimensão do cuidado e criação na clínica. Nesse caso, o terapeuta coloca-se como disponível afetivamente a ser a alteridade que permita a emergência da singularidade do sujeito (SAFRA, 2004), adaptando-se de modo suficientemente 
bom às suas necessidades (WINNICOTT, 1993[1955]). O trabalho clínico permeia a criação deste espaço de mediação, no qual o usuário é respeitado em sua manifestação criativa, marcada por seu caráter popular. Este espaço de mediação diferencia-se das outras modalidades de oferta assistencial "para" os usuários, situando-se em uma construção de saúde mental "com" estes, marcado pelo encontro afetivo. Como Freire (2005, p. 58) aponta "Ninguém liberta ninguém. Ninguém se liberta sozinho: todos nos libertamos em comunhão". É na criação de um contexto no qual o sujeito sinta-se à vontade para expressar-se a partir de sua cultura e criatividade que a autonomia é possível, possibilitando que tanto terapeuta quanto usuário libertem-se e não tenham medo da autonomia de ambos.

\section{CONSIDERaÇões FINAIS}

Este artigo se propôs a gerar questionamentos sobre a construção de uma clínica sensível a diferentes modos de sofrimento psíquico grave, que reconheça os movimentos de conformismo e resistência que permeiam a cultura popular. Portanto, ressaltamos a necessidade de as práticas em saúde mental terem maior criticidade e autonomização - do usuário e do profissional - como organizadoras do cotidiano, enfrentando o desafio de desinstitucionalização da loucura. Vemos que a Reforma Psiquiátrica ainda está buscando estabelecer dispositivos clínicos que deem conta de desconstruir - no cotidiano e no plano micropolítico - os "desejos de manicômio" (ALVERGA; DIMENSTEIN, 2006). Estes não se referem a algo que pode ser controlado intencionalmente, nem que pode ser superado completamente. Pelo contrário, exigem que o trabalhador de saúde mental analise sua implicação e seus desejos de confinar e excluir a diferença. Esse cuidado é um dos instrumentos à autonomização e ao fazer criativo de sujeitos em sofrimento psíquico grave.

Esperamos que o presente estudo permita o aprofundamento dos modos de escuta e presença sensível a aspectos da cultura popular, assim como possibilite que os profissionais dos serviços de saúde mental possam fortalecer recursos dos usuários nos tratamentos. Por outro lado, reconhecemos as limitações deste estudo, visto que são necessários estudos que proponham intervenções clínicas em metodologias que privilegiem aspectos da cultura popular, como acontece na proposta dos Círculos de Cultura (FREIRE, 1983[1967]). Do mesmo modo, vemos a necessidade de que sejam realizados estudos que discutam a utilização dos recursos clínicos da cultura popular em diferentes dispositivos da Reforma Psiquiátrica como os grupos terapêuticos e as visitas domiciliares. 


\section{REFERÊNCIAS}

ABRAM, J. A linguagem de Winnicott: dicionário das palavras e expressões utilizadas por Donald W. Winnicott. Rio de Janeiro: Revinter, 2000.

ALVERGA, A. R.; DIMENSTEIN, M. A. A reforma psiquiátrica e os desafios da desinstitucionalização da loucura. Interface - comunic., saúde, educ., Rio de Janeiro, v. 10, n.20, p. 299-316, jul./dez. 2006.

BOLTANSKI, L. As classes sociais e o corpo. Rio de Janeiro: Graal, 1979.

BRAGA, F. W. A cultura popular como recurso clínico na atenção ao sofrimento psíquico grave. Dissertação (Mestrado) - Universidade de Brasília, Brasília, 2012.

BRASIL. Ministério da Saúde. Relatório Final da IV Conferência Nacional de Saúde Mental Intersetorial. Brasília: Conselho Nacional de Saúde, 2010.

BRASIL. Ministério da Saúde. Saúde Mental em dados - 8., ano VI, no 8, informativo eletrônico. Brasília, 2011.

CALADO, A. J. F. Memória Histórica e Movimentos Sociais: ecos libertários de heresias medievais na contemporaneidade. João Pessoa: Idéia, 1999.

CHAUI, M. Conformismo e Resistência: aspectos da cultura popular no Brasil. 3. ed. São Paulo: Brasiliense, 1993.

COSTA, I. I. (Org.). Crises psíquicas do tipo psicótico: diferenciando e distanciando sofrimento psíquico grave de "psicose" In: . Da psicose aos sofrimentos psíquicos graves: caminhos para uma abordagem complexa. Brasília: Kaco, 2010. p. 57-63.

FERENCZI, S. Elasticidade da técnica psicanalítica (1928). In: Psicanálise IV. São Paulo: Martins Fontes, 1992. p. 25-36.

FREIRE, P. Educação como prática de liberdade (1967). 14. ed. Rio de Janeiro: Paz e terra, 1983.

FREIRE, P. Pedagogia do Oprimido (1974). 46. ed. Rio de Janeiro: Paz e Terra, 2005.

FREIRE, P. Ação Cultural para a Liberdade e outros escritos (1976). 14. ed. Rio de Janeiro: Paz e Terra, 2011.

FREIRE, P. Pedagogia da Esperança: um reencontro com a Pedagogia do Oprimido. Rio de Janeiro: Paz e Terra, 1992. 
GODOY, L. B. Uma veste para nossos sonhos: o lugar da cultura no pensamento winnicottiano. In: FERREIRA, A. M. (Org.). Espaço Potencial Winnicott: diversidade e interlocução. São Paulo: Landy, 2007. p. 98-117.

GUATTARI, F. Revolução Molecular: pulsações políticas do desejo. 3. ed. São Paulo: Brasiliense. 1987.

KUPERMANN, D. Presença Sensivel: cuidado e criação na clínica psicanalítica. Rio de Janeiro: Civilização Brasileira, 2008.

LANCETTI, A. Clínica Peripatética. SaúdeLoucura; 20. Série Políticas do Desejo. 3. ed. São Paulo: Hucitec, 2008.

LIMA, V. A. Comunicação e Cultura: as ideias de Paulo Freire. Rio de Janeiro: Paz e Terra, 1981.

MARX, K.; ENGELS, F. O Manifesto do partido comunista (1847). 5. ed. São Paulo: Paz e Terra, 1999.

MOFFATT, A. Psicoterapia do Oprimido: Ideologia e técnica da psicoterapia popular. 3. ed. São Paulo: Cortez, 1982.

PITTA, A. M. F. Um balanço da Reforma Psiquiátrica Brasileira: Instituições, Atores e Políticas. Ciência \& Saúde Coletiva, Rio de Janeiro, v. 16, n. 12, p. 4579-4589, 2011.

ROLNIK, S. Clínica Nômade. In: EQUIPES DE ACOMPANHANTES TERAPÊUTICOS DO INSTITUTO A CASA. (Org.). Crise e Cidade: acompanhamento terapêutico. São Paulo: EDUC, 1997. p. 83-97.

ROPA, D.; DUARTE, L. F. D. Considerações teóricas sobre a questão do "atendimento psicológico" às classes trabalhadoras. In: FIGUEIRA, S. A. (Org.) Cultura da Psicanálise. São Paulo: Brasiliense, 1985. p. 178-201.

SAFRA, G. A loucura como ausência de cotidiano. Psyche, São Paulo, v. 2, n. 2, p. 99-108, 1998.

SAFRA, G. A pó-ética na clínica contemporânea. Aparecida: Idéias e Letras, 2004.

SAFRA, G. A hermenêutica na situação clínica: o desvelar da singularidade pelo idioma pessoal. São Paulo: Sobornost, 2006.

VASCONCELOS, E. M. (Org.). Atenção em Saúde Mental inspirada na cultura e nas lutas populares: indicações a partir da antropologia do nervoso e de duas experiências locais no Brasil. In: . Abordagens Psicossociais: Reforma 
Psiquiátrica e Saúde Mental na Ótica da Cultura e das Lutas Populares. São Paulo: Hucitec, 2008. v. 2, p. 229-289.

WINNICOTT, D. W. Desenvolvimento Emocional Primitivo (1945). In: Textos Selecionados - da Pediatria à Psicanálise. Rio de Janeiro: Francisco Alves, 1993. p. 269-285.

WINNICOTT, D. W. Psicose e Cuidados Maternos (1952). In: . Textos Selecionados - da Pediatria à Psicanálise. Rio de Janeiro: Francisco Alves, 1993. p. 375-387.

WINNICOTT, D. W. (1954) Aspectos clínicos e metapsicológicos da regressão dentro do setting psicanalítico. In: . Textos Selecionados - da Pediatria à Psicanálise. Rio de Janeiro: Francisco Alves, 1993, p. 459-481.

WINNICOTT, D. W. Aspectos clínicos e metapsicológicos da regressão dentro do setting psicanalítico (1954). In: . Textos Selecionados - da Pediatria à Psicanálise. Rio de Janeiro: Francisco Alves, 1993. p. 459-481.

WINNICOTT, D. W. Variedades clínicas da transferência (1955). In: Textos Selecionados - da Pediatria à Psicanálise. Rio de Janeiro: Francisco Alves, 1993. p. 483-489.

WINNICOTT, D. W. Os objetivos do tratamento psicanalítico (1962). In: . O ambiente e os processos de maturação: estudos sobre a teoria do desenvolvimento emocional. Porto Alegre: Artmed, 1983. p. 152-155.

WINNICOTT, D. W. Os doentes mentais na prática clínica (1963). In: . $O$ ambiente e os processos de maturação: estudos sobre a teoria do desenvolvimento emocional. Porto Alegre: Artmed, 1983. p. 196-206.

WINNICOTT, D. W. Playing and Reality (1971). London: Tavistock, 1992.

WINNICOTT, D. W. Tudo começa em casa. 5. ed. São Paulo: Martins Fontes, 2011.

Recebido em: 01 de fevereiro de 2011 Aceito em: 15 de maio de 2013 